\title{
O CONCEITO DE ANGÚSTIA EM FREUD E WINNICOTT: CONSIDERAÇÕES HEIDEGGERIANAS.
}

\author{
$\underline{\text { Patrícia Catarine Silva Pinheiro }}{ }^{1}$; Caroline Vasconcelos Ribeiro ${ }^{2}$
}

\author{
1. Bolsista PIBIC/CNPq, Graduando em Psicologia, Universidade Estadual de Feira de Santana, e-mail: \\ nine.persons@hotmail.com \\ 2. Orientadora: $\mathrm{Dr}^{\mathrm{a}}$ Caroline Vasconcelos Ribeiro, Departamento de Ciências Humanas e Filosofia, Universidade \\ Estadual de Feira de Santana, e-mail: carolinevasconcelos@hotmail.com
}

PALAVRAS-CHAVE: Angústia, Freud, Heidegger, Winnicott.

\section{INTRODUÇÃO}

Este resumo apresenta resultados de uma pesquisa que teve por objetivo investigar o conceito de angústia na psicanálise de Freud e de Winnicott, tendo como referencial de análise a filosofia de Heidegger. Procuramos direcionar o nosso olhar para as bases ontológicas presentes nas formulações freudianas e winnicottianas sobre o conceito de angústia. Em Freud existem duas teorias a respeito do conceito de angústia. Na obra Inibições, sintomas e angústia o psicanalista aborda, num primeiro momento, o termo como um afeto decorrente do mecanismo de recalque, o qual é visto como "uma tentativa de fuga" (FREUD, 1996a, p. 96). Em um segundo momento, a angústia é considerada um afeto anterior e causador do recalque, por isso, equivale a um sinal de que o princípio regulador do aparato psíquico - que visa a obtenção de prazer e evitar o desprazer - em algum momento falhou. Freud (1996a, p. 111) esclarece que "a força motriz do recalque é o medo de castração" envolvido no Complexo de Édipo. Para o pediatra e psicanalista inglês Donald Winnicott, a angústia deve ser descrita a partir de momentos que antecedem à capacidade de ser submetido ao recalque e ao medo da castração. O olhar winnicottiano está baseado na vulnerabilidade e no grau de dependência do bebê humano em relação ao ambiente que lhe provê cuidados. Para ele, o amadurecer humano passa pelas fases de dependência absoluta, dependência relativa e rumo à independência. Um padrão de falhas ambientais pode obstacularizar o amadurecimento psíquico e, na fase de extrema dependência, expor o bebê a angústias impensáveis. Tais angustias são denominadas impensáveis porque se referem a um momento pré-verbal e pré-representacional, em que ainda não existe $\mathrm{Eu}$ integrado. Enquanto a angústia, para Freud, acontece a uma criança de 3 a 5 anos capaz de vivenciar conflitos pulsionais relativos à ameaça da castração, para Winnicott, a angústia se passa nos primeiros meses de vida do neonato e se refere a uma reposta a falhas na provisão ambiental. Em nossa pesquisa nos questionamos: a diferença entre os conceitos de angústia refere-se somente a uma distinção temporal entre ambas ou se trata de uma visão acerca do ser humano radicalmente diferente? Será que a divergência de perspectiva entre Freud e Winnicott se restringe ao modo como versam sobre o conceito de angústia ou esta diferença alcança as bases ontológicas de suas teorias? $\mathrm{O}$ que está em jogo é apenas uma questão de terminologia ou uma radical diferença acerca do modo de conceber e descrever o ser humano? Essas indagações guiaram os passos de nossa pesquisa.

\section{MATERIAL E MÉTODOS OU METODOLOGIA (ou equivalente)}

Esta pesquisa é de natureza bibliográfica, sendo assim, buscamos na literatura primária - em Freud, Winnicott e Heidegger - as principais ideias e argumentos que guiaram nossa investigação. Além dos autores principais, recorremos a obras 
pesquisadores que se debruçam sobre o pensamento destes teóricos, a saber, Elsa Dias, Loparic, Fulgencio, Garcia-Roza, Pisetta e Santos. Dividimos nossos passos metodológicos em três etapas: em um primeiro momento voltamos nossa atenção para o estudo do termo angústia na literatura freudiana. Para tanto, utilizamos as obras Inibições, sintomas e angústia (1996a), Três ensaios sobre a teoria da sexualidade (1996b), A dissolução do Complexo de Édipo (1996c), O caso pequeno Hans (1996d), dentre outras que tratam do conceito de angústia e dos conceitos metapsicológicos envolvidos em sua formulação. Para o estudo da teoria psicanalítica de Freud recorremos aos comentários de Garcia-Roza (1995), Pisetta (2008) e Assoun (1983). Num segundo momento, examinamos a psicanálise de Winnicott e sua maneira de abordar o amadurecimento humano sem recorrer à teoria freudiana do desenvolvimento sexual e à metapsicologia. Com o fito de especificar a natureza da teoria do amadurecimento emocional usamos os seguintes artigos de Winnicott: Memórias do nascimento, Trauma do nascimento e ansiedade (1949), A preocupação materna primária (1956), Notas sobre normalidade e angústia (1931), O uso do objeto no contexto de 'Moisés e o Monoteísmo' (1969), Distorção do ego em termos de falso e verdadeiro self (1960a), O relacionamento inicial entre uma mãe e seu bebê (1960b) e A comunicação entre o bebê $e$ a mãe e entre a mãe $e$ o bebê: convergências $e$ divergências (1968). Para nos auxiliar na compreensão da teoria winnicottiana exploramos os escritos: Da sobrevivência do analista (2002), A teoria do Amadurecimento de D. W. Winnicott (2003), da psicanalista Elsa Dias e Apontamentos sobre as angústias impensáveis em Winnicott (2011), Pressupostos conceituais para a compreensão de angústia em Freud e em Winnicott (2016) de Eder Santos. Na terceira etapa da pesquisa nos debruçamos sobre a filosofia de Heidegger com o intuito de conferir um olhar ontológico à discussão. Para tanto, tomamos como base a obra Seminários de Zollikon (2001). Para o esclarecimento da crítica ontológica de Heidegger à psicanalise, recorremos a obras dos pesquisadores do campo da "Filosofia da Psicanalise", especificamente, Zeljko Loparic e Leopoldo Fulgencio. Para análise dos conceitos relacionados à pesquisa recorremos a dicionários como: Dicionário Heidegger (Inwood, 2002), Vocabulário de Psicanálise (Laplanche e Pontalis, 2001), A linguagem de Winnicott (Abram, 1996).

\section{RESULTADOS E/OU DISCUSSÃO (ou Análise e discussão dos resultados)}

Percebemos diferenças marcantes entre a concepção freudiana e winnicottiana sobre a angústia. A formulação freudiana sobre a angústia é sustentada por um modelo de base pulsional-energética que relaciona seu surgimento ao Complexo de Édipo. Ao descrever a angústia, Freud fala de fatores que impedem a excitação sexual ser elaborada psiquicamente e descarregada. Em sua formulação, se serve dos conceitos metapsicológicos como: pulsão, aparelho psíquico, repressão e inconsciente. É justamente a teoria metapsicológica de Freud que é alvo da crítica de Heidegger (2001). Para o filósofo alemão, esta teoria se inspira no modelo procedimental das ciências naturais e na filosofia neokantiana. Heidegger considera que Freud é um arauto modelo científico-natural, já que faz uso de uma semântica fisicalista para descrever fenômenos psíquicos. Sem se servir deste tipo de semântica, sem recorrer à terminologia metapsicológica, Winnicott formula o conceito de angústia impensável, cuja emergência se deve a falhas nos cuidados iniciais com o bebê. Tais angústias não decorrem do medo de castração, não são relativas à triangulação edipiana. $O$ que está em jogo neste conceito é a relação com o ambiente facilitador do amadurecimento e não as vicissitudes da libido e os desejos incestuosos. Winnicott descreve da seguinte maneira o tipo de sensação que se passa num bebê exposto a esse tipo de angústia: 1) ser feito em pedaços; 2) cair para sempre; 3) completo isolamento, devido à inexistência de 
qualquer forma de comunicação; 4) disjunção entre psique e soma (WINNICOTT,1968, p.88). Posto que se referem a momentos muito precoces, tais angústias dizem respeito à qualidade da maternagem, refletem a ausência de confiabilidade e de constância do ambiente na fase da dependência absoluta. Como nesta fase o lactente tem como tarefa a conquista da condição de integração, o corte na continuidade de ser lhe expõe à ameaça de aniquilação e não à de castração.

\section{CONSIDERAÇÕES FINAIS (ou Conclusão)}

À luz da filosofia de Heidegger concluímos que a linguagem utilizada por ambos psicanalistas para abordar a angústia está ancorada em pressupostos ontológicos diferentes, ou seja, em visões diferentes sobre o ser humano e sobre a linguagem para descrever os fenômenos humanos. Na perspectiva freudiana temos: a centralidade do Complexo de Édipo, a teoria da sexualidade, a descrição do desenvolvimento a partir de fases psicossexuais, o entendimento do psiquismo como um aparelho e da angústia como uma reação à castração. Na winnicottiana: a centralidade da provisão ambiental na relação mãe-bebê, a teoria do amadurecimento humano, as fases de dependência em relação ao ambiente, a ideia de o que está em jogo na angústia impensável não é o adiamento da satisfação pulsional, mas a aniquilação do continuar-a-ser do bebê. Notamos que a teoria winnicottiana do amadurecimento pessoal descreve o amadurecer humano sem recorrer ao modelo científico-natural que impregna a metapsicologia. $\mathrm{O}$ seu conceito de angústia impensável não se serve da semântica metapsicológica e sua visão de ser humano não recorre à ideia de uma máquina psíquica movida por uma força constante (pulsão). Isso nos faculta dizer que não se trata apenas de diferenças conceituais e temporais em relação ao termo angústia, mas de diferenças ontológicas na própria formulação do termo. Como Winnicott não recorre ao modelo metapsicológico de explicação dos fenômenos, acreditamos que a crítica ontológica de Heidegger direcionada à Psicanálise de Freud, não pode ser dirigida à Psicanálise de Winnicott.

\section{REFERÊNCIAS}

ABRAM. J. A linguagem de Winnicott: dicionário das palavras e expressões utilizadas por. Donald W. Winnicott. Rio de Janeiro, Editora Revinter, 1996.

ASSUON, Paul Laurent. Introdução à epistemologia freudiana. Rio de Janeiro: Imago, 1983.

DIAS, Elsa Oliveira. Da sobrevivência do analista. Revista Natureza Humana v. 4, n. 2 , p. 341-362, 2002.

DIAS, Elsa Oliveira. A teoria do Amadurecimento de D. W. Winnicott. Rio de Janeiro. Editora Imago: 2003.

FREUD, S. Inibições, sintomas e ansiedade. In: Edição Standard brasileira das obras completas de Sigmund Freud. Rio de Janeiro: Imago Editora, 1996a Vol. XX.

FREUD, S. Três ensaios sobre a teoria da sexualidade. In: Edição Standard brasileira das obras completas de Sigmund Freud. Rio de Janeiro: Imago Editora, 1996b. Vol. VI.

FREUD, S. A dissolução do complexo de Édipo. In: Edição Standard brasileira das obras completas de Sigmund Freud. Rio de Janeiro: Imago Editora, 1996c Vol. XIX.

FREUD, S. Duas Histórias Clínicas (O Pequeno Hans e o Homem dos Ratos). In Edição standard brasileira das obras psicológicas completas de Sigmund Freud. Rio de Janeiro: Imago Editora, 1996d Vol. X. 
FULGENCIO, L. As Especulações metapsicológicas de Freud. In: Natureza Humana - Revista Internacional de Filosofia e Psicanálise. São Paulo: EDUC, v. 3 n. 1, 2003.

FULGENCIO, L. Winnicott e a metapsicologia, São Paulo: EDUC, 2006.

HEIDEGGER, M. Seminários de Zollikon. Tradução de GabriellaArnhold, Maria de Fátima de Almeida Prado. - São Paulo: EDUC; Petrópolis, RJ: Vozes, 2001.

LAPLANCHE, J. \& PONTALIS, J.B. Vocabulário de psicanálise. Tradução: Pedro Tamen. São Paulo: Martins Fontes, 2001.

LOPARIC; Z. Esboço do paradigma Winnicottiano. In: Cadernos de História e Filosofia da Ciência, Campinas, Série 3, v. 11, n. 2, 2001.

LOPARIC; Z. De Freud a Winnicott: aspectos de uma mudança paradigmática. In: Natureza Humana, v. 8, 2006.

PISETTA, Maria Angélica A. Considerações sobre as Teorias da Angústia em Freud. Revista Psicologia Ciência e Profissão, v.28, n 2, 2008, p. 404-413.

SANTOS, Eder Soares. Apontamentos sobre as angústias impensáveis em Winnicott. Revista de Filosofia, editora Aurora, Curitiba, v. 23, n. 33, 2011.

SANTOS, Eder Soares. Pressupostos conceituais para a compreensão de angústia em Freud e em Winnicott. In: Revista Natureza Humana, São Paulo, v. 18, n. 2, 2016.

WINNICOTT. D. W. Notas sobre normalidade e ansiedade". In: Da pediatria à psicanálise, obras escolhidas. Rio de Janeiro: Editora Imago, 1931.

WINNICOTT. D. W. Memórias do nascimento, Trauma do nascimento e ansiedade. In: Da pediatria à psicanálise, obras escolhidas. Rio de Janeiro: Editora Imago, 1949.

WINNICOTT. D. W. Distorção do ego em termos de falso e verdadeiro self. In: Winnicott, (1979) O Ambiente e os Processos de Maturação. Porto Alegre: Artes Médicas, 1960a.

WINNICOTT. D. W. A comunicação entre o bebê e a mãe e entre a mãe e o bebê: convergências e divergências. In: Os bebê e suas mães. São Paulo: Martins Fontes, 1968.

WINNICOTT. D. W. O relacionamento inicial entre uma mãe e seu bebê. In: A família e o desenvolvimento individual. Belo Horizonte: Interlivros, 1960c.

WINNICOTT. D. W. O uso do objeto no contexto de 'Moisés e o Monoteísmo'. In: Explorações Psicanalíticas: D.W. Winnicott. Porto Alegre: Artes Médicas Sul, 1969. 